\title{
CAPÍTULO 18: CONHECIMENTO EM MOVIMENTO: PROFESSOR ESTUDA BEM-ESTAR ANIMAL E LEVA SAÚDE PARA SEUS ALUNOS
}

\section{CAPÍTULO 18: EL CONOCIMIENTO EN MOVIMIENTO: EL MAESTRO ESTUDIA EL BIENESTAR ANIMAL Y LLEVA LA SALUD PARA SUS ESTUDIANTES}

\section{CHAPTER 18: KNOWLEDGE ON THE MOVE: TEACHER STUDIES ANIMAL WELFARE AND TAKES HEALTH FOR HIS STUDENTS}

Gilberto Francisco da Silva ${ }^{1}$; Adrielle Ewerlyn Cirino Gomes ${ }^{2}$; Adrielly Regina Albuquerque de Souza ${ }^{3}$ Laércio Nogueira Medeiros; ${ }^{4}$ Viviane da Silva Medeiros ${ }^{5}$

DOI: https://doi.org/10.31692/978-65-88970-05-8.219-222

\section{INTRODUÇÃO}

O Projeto de extensão Xerimbabo desde 2012 atua na educação em saúde com crianças, trabalhando os conteúdos relacionados às zoonoses e ao bem-estar animal (SILVA et al, 2017). Nestes anos, observamos que os professores das turmas participantes de ensino fundamental, também demonstravam interesse nos temas abordados.

Segundo os Parâmetros Curriculares Nacionais (PCN), a educação de ciências prevê nas séries do ensino fundamental e médio o ensino de saúde de forma transversal, de modo que, os alunos aprendam os cuidados básicos de higiene para a manutenção da saúde. Durante o projeto de extensão, muitos professores que assistiam às apresentações para as crianças, tinham formação em áreas das licenciaturas, como pedagogia, história, artes, ou mesmo biologia, mas não se sentiam seguros na área de educação em saúde, que trata de infecções zoonóticas ou mesmo bem-estar animal. Desta forma, iniciamos um novo projeto para capacitar professores da educação básica das cidades do interior do Rio Grande do Norte e, através da divulgação nessas cidades, foi possível nós participarmos do projeto de extensão do Programa Agrojundiaí intitulado: Bem-estar animal e prevenção de zoonoses no âmbito das escolas da rede básica de ensino - capacitando trabalhadores da educação e a partir desta capacitação experienciamos esta vivência.

\footnotetext{
${ }^{1}$ Graduado em Ciências Biológicas, UNIFACEX, gilbertosilvalp@live.com

${ }^{2}$ Graduanda em Zootecnia, UFRN, adriellegomes2002@gmail.com

3 Técnico em Aquicultura, Escola Agrícola de Jundiaí/UFRN, adriellyregina929@gmail.cot

4 Tecnologia Aplicada a Educação, IFRN, laerciomedeiros2015@gmail.com

${ }^{5}$ Doutora em Psicobiologia, Escola Agrícola de Jundiaí/UFRN, vivianemedeiros.eaj@gmail.com
} 


\section{RELATO DE EXPERIÊNCIA}

Esta vivência foi realizada na Escola Municipal Professor José Luiz Rodrigues (EMPJLR), no Sítio Mandu I, na Zona Rural da cidade de Lagoa de Pedras-RN, que de acordo o Instituto Brasileiro de Geografia e Estatística (IBGE, 2020) tem a população estimada para 2020 de 7.584 pessoas, resultando numa densidade demográfica 64,46 hab./km².

Na EMPJLR lecionamos ciências a 147 alunos distribuídos em cinco turmas do ensino fundamental, três $6^{\circ}$ anos, um $7^{\circ}$ ano e uma turma de $5^{\circ}$ período do Ensino de Jovens e Adultos (EJA).

Através da Secretaria de Educação da Cidade, tomamos conhecimento da capacitação para professores da rede básica promovido e ofertado pela Escola Agrícola de Jundiaí (EAJ). Ao iniciarmos a capacitação, realizada integralmente de forma remota, o interesse foi de agregarmos conhecimentos de cunho científico e social, e consequentemente aplicá-los nas aulas de ciências.

Já no primeiro momento da capacitação, tivemos o contentamento de compreender noções de Bem-estar animal (BEA), assim como o seu antônimo: maltrato animal, e zoonoses. Também, foi possível perceber os impactos negativos e benéficos que a prática do BEA pode trazer aos animais humanos ou não humanos. Como impacto negativo tem-se a interferência no comportamento do animal e das pessoas que com ele convivem. Ao preservar o BEA possibilitamos o benefício de uma vida com menos estresse para ambos. Essa redução de estresse em animais de produção, por exemplo, pode diminuir sofrimento como claudicação por exemplo em vacas leiteiras (BOND et al, 2012).

É bem válido abordarmos este assunto em sala de aula, pois há animais de ruas que ficam nas proximidades da escola ou até mesmo dentro do prédio escolar, o que representa um risco à nossa saúde por acidentes e zoonoses. Estes animais muita das vezes até são alimentados, mas faltam outros cuidados básicos do BEA, tais como a vacinação, banho e outros cuidados de higienização, além disso saber se este animal, seja cachorro ou gato, ou ainda outro animal doméstico, tem um tutor e/ou um lugar para se abrigar.

A partir dessa necessidade observada e já utilizando os conhecimentos da capacitação de extensão, utilizamos um dos temas abordados na oficina de extensão. Optamos pelo Bemestar Animal (Figura 1), apresentado através de ensino remoto para alunos de todas as turmas. 
Figura 1: Imagem da sala do google meet com o tema apresentado Bem-estar animal.

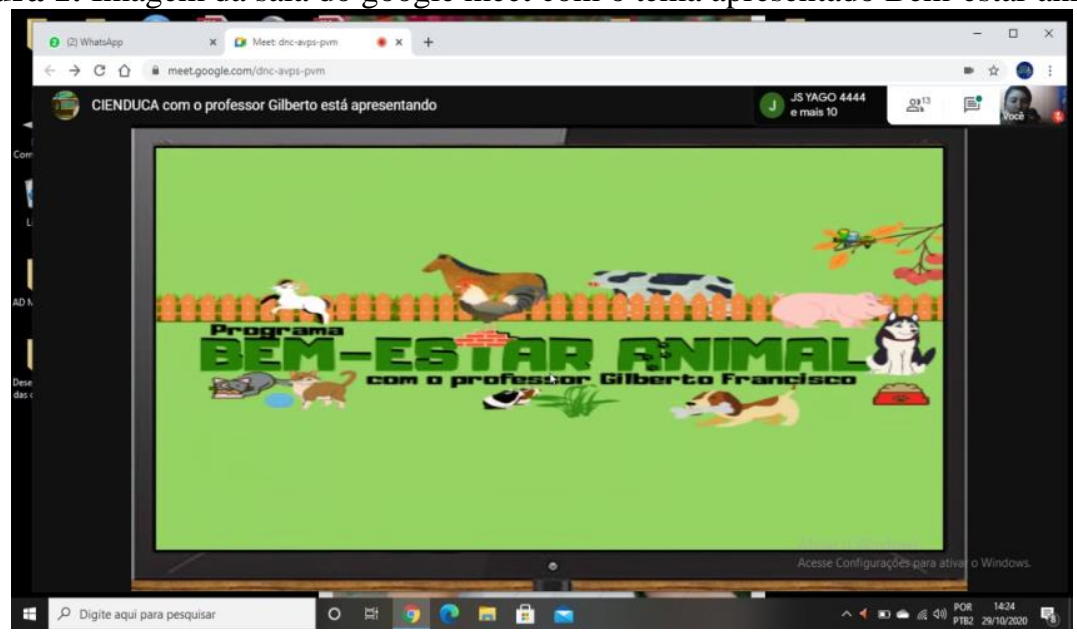

Fonte: Própria (2020).

Ainda nesta aula on-line, via Google Meet, os conceitos de bem-estar animal e as "cinco liberdades" foram apresentados através de slides com o uso de figuras e informes interativos, um vídeo curto sobre uma reportagem sobre maus tratos e ao final uma atividade escrita (Figura 2).

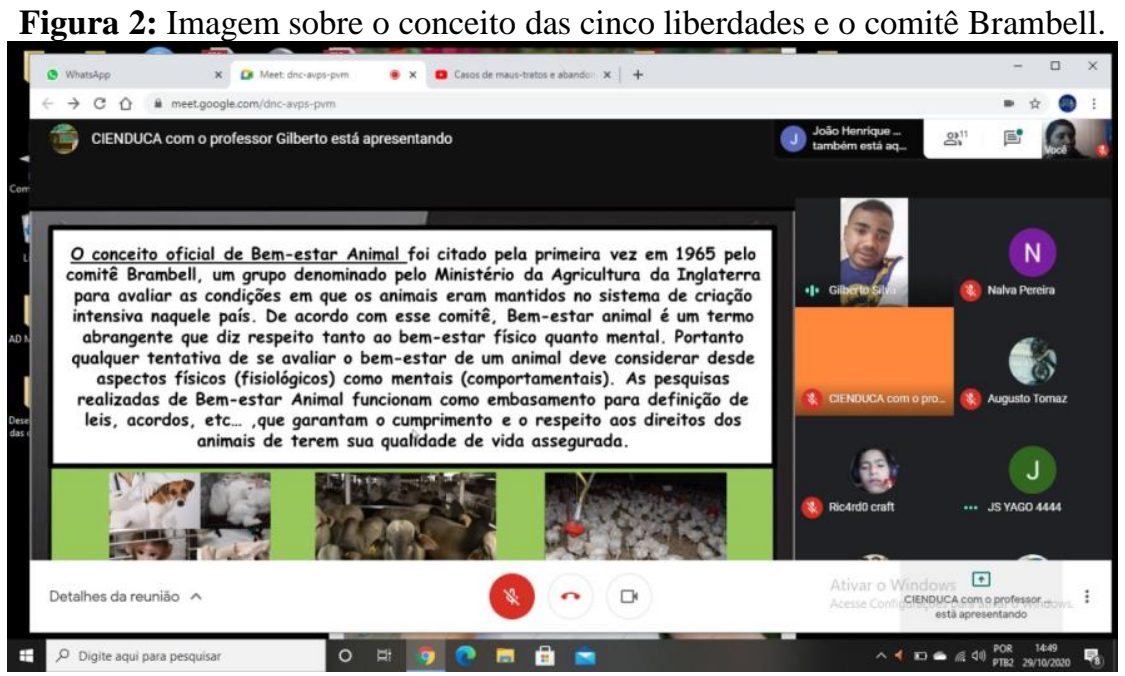

Fonte: Própria (2020).

Participaram desta atividade 7 alunos. Apesar de ter sido na forma remota, foi de grande valia aplicar esta aula para os alunos, uma vez que, por meio do conhecimento prévio que os mesmos tinham, surgiram perguntas e interações, mostraram-se sensibilizados no decorrer da aula, principalmente ao ser-lhes apresentadas situações graves como as rinhas de cães e de galos, também em situações extremas do sistema intensivo de criação. Ao final da aula foi passada uma avaliação, houve um retorno positivo, mesmo daqueles alunos que não puderam assistir a aula. Observamos que a disponibilização do material de estudo nos grupos de redes sociais de cada turma, possibilitou a todos responderem a atividade com êxito. 


\section{CONCLUSÕES}

Projetos de extensão universitários são uma oportunidade de entrada de novos conhecimentos para grupos de profissionais, que por sua área de atuação, muitas vezes em cidades de interior, não teriam acesso a estas informações.

Neste ano 2020, mesmo com a pandemia, causada pela COVID-19, foi possível a realização da capacitação de forma virtual. Da mesma forma, o conhecimento em movimento possibilitou levar novas informações aos estudantes de ensino fundamental. Numa corrente de aprendizagem.

A replicação desses conhecimentos para crianças é uma forma de instruí-las e também de compartilhar o que aprenderam com seus familiares e amigos. Assim, contribuindo para formação de uma sociedade mais preocupada com o ambiente e os animais que nele habitam.

Para nós foi uma experiência em ciências, em saúde, em ética para o bem-estar animal, nos tornando, através do conhecimento recebido, construído e repassado, pessoas que entendem e trabalham pela saúde única (animal, ambiental e humana).

\section{REFERÊNCIAS}

KONFLANZ C.G.; MEIRELLES M. Será a temática das zoonoses um problema de saúde pública ou um problema pedagógico?. Revista de Educação Continuada em Medicina Veterinária e Zootecnia do CRMV-SP, v. 15, n. 1, p. 80-80, 1 jan. 2017.

BOND, Guilherme Borges et al. Métodos de diagnóstico e pontos críticos de bem-estar de bovinos leiteiros. Ciência Rural, v. 42, n. 7, p. 1286-1293, 2012.

Silva, Fernanda and Silva, Maria and de Melo, Brena and Pinheiro, Maria and Medeiros, Viviane, 2017, XERIMBABO: EDUCANDO PARA UM FUTURO CONSCIENTE\}, doi = $\{10.31692 / 2526-7701 . I I C O I N T E R P D V A G R O .2017 .00555\}$.

IBGE， https://cidades.ibge.gov.br/brasil/rn/lagoa-de-pedras/panorama < visitado 04/11/2020> 